\title{
Stem cells therapy in inflammatory bowel disease
}

\author{
Venera Rakhmetova, Aida Orazbayeva
}

Department of Gastroenterology and Hepatology, JSC "National Scientific Medical Center", Astana, Kazakhstan

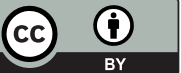

This work is licensed under a Creative Commons Attribution 4.0 International License

Received: 17-07-2017

Accepted: 24-08-2017

J CLIN MED KAZ 2017;4(46):6-10

Автор для корреспонденции: Оразбаева Аида Бекайдаровна - научный сотрудник сектора гастроэнтерологии и гепатологии, АО «Национальный научный медицинский центр», просп. Абылай хан 42 , Астана, Казахстан. Тел: +77015919086 , email: aika_ kori@mail.ru

\section{Abstract}

The article analyzes the experience of applying various stem cell pools in the treatment of inflammatory diseases of the colon. Basic and clinical studies on properties of mesenchymal stem cells and clinical effects of various technologies for their use conducted held in recent years allows to consider the mesenchymal stem cells transplantation as a new and promising direction in the treatment of ulcerative colitis.

Key words: Inflammatory bowel disease, mesenchymal stem cell, transplantation, regenerative medicine.

\section{ІШЕКТІН ІСІП КЫЗАРУ АУРУЛАРЫН ЕМДЕУДЕ БАҒАНАЛЫК ЖАСУШАЛАРДЫ ҚОЛДАНУ}

Рахметова В. С. Оразбаева А. Б.

«Ұлттық ғылыми медициналық орталығы» АҚ Гастроэнтерология және гепатология бөлімі, Астана қаласы, Қазақстан

\section{ТҰЖЫРЫМДАМА}

Мақалада тоқ ішектің ісіп қызару ауруларын емдеуде бағаналық жасушалардың әртүрлі популяциясын қолдану тәжірибесіне талдау жасалды. Мезенхималдық бағаналық жасушалардың қасиетін және оларды пайдаланудың әртүрлі технологияларының клиникалық әсерін зерделеу бойынша соңғы жылдары өткізілген іргелі және клиникалық зерттеулер мезенхималдық бағаналық жасушаларды трансплантаттауды ойық жаралы колитті емдеудегі жаңа және перспективалық бағыт ретінде қарауға мүмкіндік береді.

Негізгі сөздер: ішектің ісіп қызаруы, мезенхималдық бағаналық жасушалар, трансплантаттау, регенеративті медицина.

\section{ПРИМЕНЕНИЕ СТВОЛОВЫХ КЛЕТОК В ЛЕЧЕНИИ ВОСПАЛИТЕЛЬНЫХ ЗАБОЛЕВАНИЙ КИШЕЧНИКА}

Рахметова В. С. Оразбаева А. Б.

Отдел гастроэнтерологии и гепатологии, АО «Национальный научный медицинский центр», Астана, Казахстан.

PE3ЮME

В статье проанализирован опыт применения различных популяций стволовых клеток в лечении воспалительных заболеваний толстого кишечника. Фундаментальные и клинические исследования по изучению свойств мезенхимальных стволовых клеток и клинических эффектов различных технологий их применения, проведенные за последние годы, позволяют рассматривать трансплантацию мезенхимальных стволовых клеток как новое и перспективное направление в лечении язвенного колита.

Ключевые слова: воспалительные заболевания кишечника, мезенхимальные стволовые клетки, трансплантация, регенеративная медицина. 


\section{Введение}

Воспалительные заболевания кишечника (ВЗК) представляют одну из наиболее серьезных и нерешенных проблем в современной гастроэнтерологии. По уровню заболеваемости В3К значительно уступают другим заболеваниям органов пищеварения, но по тяжести течения, частоте осложнений и летальности они во всем мире занимают одно из ведущих положений в структуре болезней желудочнокишечного тракта [1]. Актуальность

Актуальность патологии подтверждается ростом заболеваемости среди лиц трудоспособного возраста, отсутствием специфического лечения, рецидивирующим течением, развитием угрожающих жизни осложнений, необходимостью проведения длительной, часто пожизненной, дорогостоящей терапии и неблагоприятным медикосоциальным прогнозом [2]. Распространенность ВЗК в регионах мира различна, так, частота язвенного колита (ЯК) по данным разных авторов составляет от 21 до 268 случаев, а болезни Крона (БК) от 9 до 199 случаев на 100 тыс. населения, достигая максимальных показателей в странах Скандинавии, Северной Америке, Канаде, Израиле. Прирост заболеваемости для ЯК 5-20 случаев в год, для БК - 5-15 случаев в год на 100 тыс. населения. Распространенность ЯК можно объяснить истинным приростом заболеваемости и улучшением диагностики благодаря разработке четких диагностических критериев [3]. Заболевание поражает преимущественно молодых людей (средний возраст заболевших - 20-40 лет), но может начаться в любом возрасте. У молодых пациентов отмечается более агрессивное течение и в лечении чаще применяются иммуномодуляторы и хирургическое лечение, в то время как у пациентов, у которых ЯК диагностирован позже, болезнь протекает мягче, с меньшей необходимостью в хирургии [4].

\section{Определение}

Язвенный колит, в соответствии с консенсусом ЕССО и рекомендациями Британского общества гастроэнтерологов, хроническое заболевание, приводящее к протяженному воспалению слизистой и подслизистой оболочки толстой кишки без гранулем при биопсии, поражающее прямую кишку и, в различной степени толстую кишку, характеризующуюся ремитирующим течением с периодами обострений. Также характерным признаком являются системные и внекишечные проявления [5-8].

Этиология ЯК и БК остается неизвестной, так как не обнаружено определенного инфекционного агента, пищевого антигена или иного внешнего фактора, который мог бы вызвать заболевание в эксперименте. На данный момент ВЗК считаются многофакторными заболеваниями с генетической предрасположенностью [9].

Мнение большинства исследователей о патогенетической роли кишечных антигенов при условии неадекватного ответа на них иммунной системы кишечника неизменно. Многочисленные исследования показали, что нарушения имеются практически во всех звеньях иммунной системы кишечника, начиная от барьерных функций эпителия и распознавания антигена, передачи сигнала дендритными клетками и сигнальными молекулами, презентации антигена HLA, и заканчивая функциями моноцитов-макрофагов, Т-лимфоцитов и В-лимфоцитов[10]. Давнее представление об аутоиммунном характере ВЗК в последнее время получило новое развитие благодаря сведениям о том, что комменсальная микрофлора и продукты ее жизнедеятельности служат в качестве аутоантигенов, а развитие воспаления происходит за счет потери толерантности к веществам нормальной кишечной флоры, которые обычно безвредны [11]. В пользу представления об аутоиммунном характере этой группы заболеваний свидетельствует также высокая концентрация циркулирующих иммунных комплексов (ЦИК), которые обнаруживаются у 20-40\% больных ЯК и БК, особенно при наличии внекишечных проявлений [3].

\section{Сложности в лечении}

Лечение воспалительных заболеваний толстого кишечника, включающее препараты антител к фактору некроза опухоли-альфа, к сожалению также не всегда позволяет достичь желаемого эффекта. По данным исследований, риск рецидива в течение первого года после установления диагноза ВЗК составляет 50\% при ЯК и 47\% при БК. Среди пациентов, леченных глюкокортикостероидами, лишь у $44 \%$ наблюдается стойкая ремиссия в течение первого года, в то время как у $36 \%$ формируется стероидозависимость и у $20 \%$ стероидорезистентность [12]. У больных ЯК, впервые леченных стероидными гормонами, только у 49\% наблюдался пролонгированный ответ, у 22\% развилась стероидозависимость, а у $29 \%$ возникает необходимость в колэктомии из-за резистентности к лечению [13]. Развитие тяжелых осложнений язвенного колита, оперативные вмешательства, выход на инвалидность лиц молодого возраста диктуют необходимость поиска новых решений в подходе к терапии.

\section{Стволовые клетки}

В последние десятилетия появились доказательства того, что физиологическое обновление и регенерация тканей в течение всей жизни животного и человекапроисходят благодаря стволовым клеткам. Важнейшей популяцией стволовых клеток взрослого организма являются мезенхимальные стволовые клетки (МСК) источник [14] указан в конце абзаца. Впервые эти клетки были обнаружены и выделены из стромы костного мозга источник [14] указан в конце абзаца. Считалось, что МСК костного мозга служат источником для обновления и восстановления таких соединительных тканей, как костная, хрящевая и жировая источник [14] указан в конце абзаца. В настоящий момент аналоги МСК костного мозга обнаружены и во всех других тканях источник [14] указан в конце абзаца. Благодаря подходам, позволяющим идентифицировать МСК insitu, выделять их изтканей инаконец оценивать биологические свойства, появилась возможность пересмотреть роль МСК в различных органах и тканях источник [14] указан в конце абзаца. По представлениям авторов статьи, МСК выполняют функцию сопряжения кровеносной, иммунной, гормональной и нервной систем с тканеспецифичными стволовыми клетками [14].

\section{Клеточная терапия в лечении воспалительных заболеваний кишечника}

По мнению ученых, именно клеточная терапия станет следующим поколением лекарственных средств в лечении язвенного колита и болезни Крона [20]. Первое исследование клеточной терапии при воспалительных заболеваниях кишечника (ВЗК) было ретроспективным и включало 10 пациентов с опухолями кроветворной системы, по поводу которых выполнялась трансплантация аллогенных СК с предварительной миелоабляцией. У 6 из них диагностирована 
болезнь Крона, у 4 - язвенный колит. Во всех 10 случаях достигнута полная ремиссия после трансплантации (период наблюдения составил от 3 до 117 мес.). У 1 больного развилось легкое обострение болезни Крона, купировавшееся самостоятельно. У 1 реципиента после неродственной трансплантации СК манифестировал цитомегаловирусный энтерит с последующим летальным исходом от грибковой инфекции [15]. В более позднем исследовании после трансплантации аутологичных СК длительная ремиссия констатирована у 11 из 12 пациентов с болезнью Крона, рефрактерных к проводимой терапии [16]. В ряде исследований трансплантация аутологичных гематопоэтических СК при болезни Крона продемонстрировала безопасность наряду с весьма высокой эффективностью: у большинства пациентов, рефрактерных к традиционным методам лечения, удалось индуцировать и поддерживать ремиссию $[17,18]$. R.K. Burt и соавт. установили, что комбинация клеточной терапии с циклофосфамидом также обусловливала индукцию ремиссии с прекращением диареи, уменьшением абдоминальной боли, а также улучшением лабораторных показателей и гистологической картины, свидетельствующих об уменьшении активности патологического процесса [19].

В статье Насадюк К.М. проанализированы доклинический и клинический опыт применения различных популяций стволовых клеток в лечении воспалительных заболеваний толстого кишечника [20]. В лечении болезни Крона исследуются как гемопоэтические стволовые клетки костного мозга, пуповинной и периферической крови, так и в мировой практике накоплен значительный опыт применения мезенхимальных стволовых клеток, также выделенных из костного мозга или пуповинной крови, а также амниотической жидкости, жировой ткани [20].

Анализ современной научной литературы позволяет сделать вывод, что клеточная терапия воспалительных заболеваний толстого кишечника предполагает 2 подхода:

1. Иммуносупрессия с последующей трансплантацией гемопоэтических стволовых клеток;

2. Применение мезенхимальных стволовых клеток, обладающих как иммуносупрессивным, так и регенеративным действием.

На сегодняшний день в мире зарегистрировано более 200 клинических исследований по изучению терапевтической эффективности мезенхимальных стволовых клеток, из них более 20 посвящены лечению болезни Крона и язвенного колита. Клеточную терапию провели более 1500 пациентам с воспалительными заболеваниями толстой кишки [20].

Клеточная терапия болезни Крона и язвенного колита, прежде всего, показана пациентам с резистентностью к антицитокиновой терапии, а также при гормонорезистентных и гормонозависимых формах заболеваний. Отмечено, что применение стволовых клеток при болезни Крона и неспецифическом язвенном колите позволяет уменьшить дозу глюкокортикоидов в лечении этих пациентов, также получены данные об эффективности клеточной терапии в лечении целиакии и других генетически обусловленных заболеваний кишечника [20].

По данным статьи Маянской И.В. мезенхимальные стволовые (стромальные) клетки (МСК) обладают способностью подавлять пролиферацию и активность клеток врожденного и адаптивного иммунитета, оказывая толерогенное и противовоспалительное действие. Супрессорные свойства выражены примерно одинаково у стромальных клеток, полученных из разных источников. Они не зависят от степени дифференцировки МСК и проявляются в аллогенных и ксеногенных комбинациях. Для МСК типичны отсутствие поверхностных антигенпредставляющих молекул второго типа и костимулирующихлигандов, которые необходимы для антигензависимых реакций CD4-Tлимфоцитов. Это обеспечивает гипоиммуногенностьМСК, т.е. их низкую способность активировать аллогенные Т-клетки. Ингибиторные свойства МСК связаны с присутствием противовоспалительных цитокинов, которые секретируются при активации иммунных клеток, стимулируя (праймируя) толерогенные функции МСК. Блокирующее действие определяется межклеточными контактами между МСК и их мишенями, а также зависит от гуморальных медиаторов, которые выделяются стимулированными МСК. Супрессивные эффекты МСК поддерживают гомеостаз гемопоэтических клеток костного мозга, участвуют в периферической толерантности к собственным антигенам, определяют толерогенные контакты в иммунологической системе матьплод. Гипоиммуногенность и блокирующее действие МСК играют существенную роль в современной цитотерапии, обеспечивая длительное присутствие вводимых МСК и их способность поддерживать регенерацию тканей [21].

Следует отметить, что трансплантация кроветворных стволовых клеток при хронических воспалительных заболеваниях кишечника (ВЗК), как и при других заболеваниях, является сложным комплексным методом лечения. Ограниченные клинические испытания, проводившиеся во многих медицинских и научных центрах Европы и Америки, показали, что при лечении ВЗК методом трансплантации стволовых клеток в большинстве случаев удается достичь положительного эффекта даже без проведения иммуносупрессивной терапии. Процедура лечения хорошо переносится, и у большинства больных удается достичь устойчивой, а иногда и полной ремиссии заболевания [16,22]. В настоящее время проводятся расширенные клинические испытания во многих клиниках Европы и США.

\section{Иммуномодулирующий эффрект стволо- вых клеток}

По утверждению ряда авторов $[23,24]$ аутоиммунные заболевания (АИЗ) объединяются в одну группу на основании общих особенностей патогенеза, и подходов к лечению, основой которой является иммуносупрессивная терапия. Общим звеном в патогенезе аутоимунных заболеваний являются нарушения в иммунной системе, приводящие к развитию поликлонального иммунного ответа на собственные антигены (в этом ответе участвуют В- Т- лимфоциты и макрофаги) $[25,26]$. В связи с тем, что все клетки иммунной системы происходят из единой стволовой клетки, высказана гипотеза о развитии АИЗ вследствие дефектов стволовых клеток или их ближайших потомков [27]. Это предположение подтверждают результаты экспериментальных и клинических исследований.

В части исследований показано, что трансплантация аллогенных СК обладает иммуномодулирующим эффектом: увеличивается, в частности, исходно сниженная продукция иммуноглобулинов и ряда цитокинов (TNF $\alpha$, IFN $\gamma$, IL$1,4,10)$, а также снижается образование аутоантител к нейтрофилам. Недавно установлено, что мезенхимальные СК способствуют образованию регуляторных Т-клеток и индуцируют антигензависимую пролиферацию 
последних [28]. Исследованием Л.Б. Лазебника и соавт. [29] выявлено статистически значимое снижение клинической и морфологической активности язвенного колита у 34 из 44 больных, получавших лечение мезенхимальными СК. У большинства пациентов с гормонозависимой и гормонорезистентной формами болезни клеточная терапия позволила либо снизить дозу кортикостероидов до поддерживающей, либо отменить их. Авторы констатируют, что эффективность клеточной терапии сопоставима с таковой у инфликсимаба.
Таким образом, исходя из данных анализа литературы применение стволовых клеток значительно расширяет арсенал терапевтических средств в лечении больных с воспалительными заболеваниями толстого кишечника и позволяет повысить эффективность лечения этой сложной патологии, однако до сих пор окончательно не решены вопросы о четких показаниях, оптимальных сроках и режиме введения стволовых клеток при ВЗК.

\section{Литература}

1. Khalif I.L., Loranskaya I.D., Vospalitel'nye zabolevaniya kishechnika (nespetsificheskii yazvennyi koliti, bolezn' Krona): klinika, diagnostika, lechenie (Inflammatory bowel disease (ulcerative colitis and Crohn's disease): clinic, diagnosis, treatment) [inRussian]. M: Miklosh. 2004;pp. 88.

2. Adler G. Bolezn' Krona I yazvennyi kolit (Crohn's disease and ulcerative colitis) [in Russian].M: GEOTAR-MED. 2001;pp. 527.

3. Vorob'ev G.I., Khalif I.L. Nespetsificheskie vospalitel'nye zabolevaniya kishechnika (Nonspecific inflammatory bowel disease) [in Russian]. M: Miklosh. 2008; pp 400.

4. Belousova E.A. Yazvennyi kolit i bolezn' Krona (Ulcerative colitis and Crohn's disease) [in Russian]. Tver': Izdatel'stvo «Triada».2002; pp128.

5. Gomollón F, Dignass A, Annese V, Tilg H, Van Assche G, Lindsay JO, Peyrin-Biroulet L, Cullen GJ, Daperno M, Kucharzik T, Rieder F. 3rd European evidence-based consensus on the diagnosis and management of Crohn's disease 2016: part 1: diagnosis and medical management. Journal of Crohn's and Colitis. 2016;11(1):3-25.

6. Harbord M, Eliakim R, Bettenworth D, Karmiris K, Katsanos K, Kopylov U, Kucharzik T, Molnár T, Raine T, Sebastian S, de Sousa HT. Third European Evidence-based Consensus on Diagnosis and Management of Ulcerative Colitis. Part 2: Current Management. Journal of Crohn's and Colitis. 2017; 1-24.

7. Mowat C, Cole A, Windsor A, Ahmad T, Arnott I, Driscoll R, Mitton S, Orchard T, Rutter M, Younge L, Lees C. Guidelines for the management of inflammatory bowel disease in adults. Gut. 2011;60(5):571-607.

8. Peyrin-Biroulet L, Bouhnik Y, Roblin X, Bonnaud G, Hagège H, Hébuterne X. French national consensus clinical guidelines for the management of ulcerative colitis. Digestive and Liver Disease. 2016;48(7):726-33.

9. Satsangi J. Morecroft N.B. Genetics of inflammatory bowel disease: scientific and clinical implications. Best Pract. Res. Clin. Gastroenterology.2003;17:3-18.

10. Yamamoto-Furusho JK, Podolsky DK. Innate immunity in inflammatory bowel disease. World journal of gastroenterology. 2007;13(42):5577.

11. Farell R., Pepperkorn M. Yazvennyikolit (Ulcerative colitis) [in Russian], Mezhdunarodnyi meditsinskii zhurnal.2003;1(6): http://medi.ru/doc/773012.htm.

12. Munkholm P, Langholz E, Davidsen M, Binder V. Frequency of glucocorticoid resistance and dependency in Crohn9s disease. Gut. 1994 Mar 1;35(3):360-2.

13. Faubion WA, Loftus EV, Harmsen WS, Zinsmeister AR, Sandborn WJ. The natural history of corticosteroid therapy for inflammatory bowel disease: a population-based study. Gastroenterology. 2001;121(2):255-60.

14. Kalinina N. I., Sysoeva V. Yu., Rubina K. A., Parfenova E. V., Tkachuk V.A. Annotatsiya nauchnoi stat'i «Mezenkhimal'nye stvolovye kletki v protsessa khrostaireparatsi i tkanei» (Mesenchymal stem cells in tissue growth and repair processes) [in Russian]. Acta Naturae. 2011;3(4).

15. Ditschkowski M, Einsele H, Schwerdtfeger R, Bunjes D, Trenschel R, Beelen DW, Elmaagacli AH. Improvement of inflammatory bowel disease after allogeneic stem-cell transplantation. Transplantation. 2003 May 27;75(10):1745-7.

16. Oyama Y, Craig RM, Traynor AE, Quigley K, Statkute L, Halverson A, Brush M, Verda L, Kowalska B, Krosnjar N, Kletzel M. Autologous hematopoietic stem cell transplantation in patients with refractory Crohn's disease. Gastroenterology. 2005;128(3):552-63.

17. Cassinotti A, Annaloro C, Ardizzone S, Onida F, Della Volpe A, Clerici M, Usardi P, Greco S, Maconi G, Porro GB, Deliliers GL. Autologous haematopoietic stem cell transplantation without CD34+ cell selection in refractory Crohn's disease. Gut. 2008;57(2):211-7.

18. Dryden G.W. Overview of stem cell therapy for Crohn disease. Expert. Opin. Biol. Ther. 2009;9:841-847.

19. Burt R.K., Traynor A., Oyama Y., Craig R. High-dose immune suppression and autologous hematopoietic stem cell transplantation in refractory Crohn disease. Blood. 2003;101:2064-2066.

20. Nasadyuk CM. Stem Cell Therapy In The Treatment Of Inflammatory Bowel Disease. Gastroenterology\&Hepatology: Open Access. 2014;1(1):00006. 
21. I.V. Mayanskaya, A.Yu. Goganova, N.I. Tolkachova, V.I. Achkinazi, A.N. Mayansky. Immunosuppressive activity of mesenchymal stem (stromal) cells [In Russian]. Immunology. 2013;34(2):122-128

22. Hawkey C. J. Stem cell transplantation for Crohn's disease. Best Pract Res Clin. Haematol.2004;17(2):317-325.

23. Kolb HJ, Schattenberg A, Goldman JM, Hertenstein B, Jacobsen N, Arcese W, Ljungman P, Ferrant A, Verdonck L, Niederwieser D. Graft-versus-leukemia effect of donor lymphocyte transfusions in marrow grafted patients. European Group for Blood and Marrow Transplantation Working Party Chronic Leukemia. Blood. 1995;86(5):2041-50.

24. McGuire WP, Hoskins WJ, Brady MF, Kucera PR, Partridge EE, Look KY, Clarke-Pearson DL, Davidson M. Cyclophosphamkte and cisplatin compared with paclitaxel and cisplatin in patients with stage III and stage IV ovarian cancer. $N$. Engl. J. Med. 1996;334(1):1-6.

25. Nasonov E. L. Sovremennye napravleniya immunologicheskikh issledovanii pri khronicheskikh vospalitel'nykh i autoimmunnykh zabolevaniyakh cheloveka (Modern trends of immunological studies in chronic inflammatory and autoimmune diseases of man) [in Russian]. Ter. arkhiv. 2001;73(8):43- 46.

26. Nazarenko G. I., Kishkun A. A. Klinicheskaya otsenka rezul'tatov laboratornykh issledovanii (Clinical evaluation of laboratory results) [in Russian]. M.: Meditsina. 2002; pp 544.

27. Shevchenko Yu. L., Boitsov S. A., Novik A. A., Lyadov K. V. Kontseptsiya kletochnoi terapii autoimmunnykh zabolevanii (The concept of cell therapy of autoimmune diseases) [in Russian]. Vestn.Ros. AMN.2004;9:40-4.

28. Singh UP, Singh NP, Singh B, Mishra MK, Nagarkatti M, Nagarkatti PS, Singh SR. Stem cells as potential therapeutic targets for inflammatory bowel disease. Frontiers in bioscience (Scholar edition). 2010;1:993-1008.

29. Lazebnik L.B., Knyazev O.V., Konoplyannikov A.G. i dr. Allogennye mezenkhimal'nye stromal'nye kletki v lechenii bol'nykh yazvennym kolitom: dva goda nablyudeniya (Allogenic mesenchymal stromal cells in the treatment of patients with ulcerative colitis: two years of follow-up) [in Russian]. Klin.eksperiment. gastroenterol.2010;11:3-15.

How to cite this article: Venera Rakhmetova, Aida Orazbayeva. Stem cells therapy in inflammatory bowel disease [in Russian]. J Clin Med Kaz. 2017;4(46):6-10. 